Article

\title{
Optimal Operation of Combined Energy and Water Systems for Community Resilience against Natural Disasters
}

\author{
Govind Joshi * and Salman Mohagheghi
}

check for updates

Citation: Joshi, G.; Mohagheghi, S. Optimal Operation of Combined Energy and Water Systems for Community Resilience against Natural Disasters. Energies 2021, 14, 6132. https://doi.org/10.3390/ en14196132

Academic Editor: José Matas

Received: 26 July 2021

Accepted: 22 September 2021

Published: 26 September 2021

Publisher's Note: MDPI stays neutral with regard to jurisdictional claims in published maps and institutional affiliations.

Copyright: (c) 2021 by the authors. Licensee MDPI, Basel, Switzerland. This article is an open access article distributed under the terms and conditions of the Creative Commons Attribution (CC BY) license (https:// creativecommons.org/licenses/by/ $4.0 /)$.
Electrical Engineering Department, Colorado School of Mines, Golden, CO 80401, USA; smohaghe@mines.edu * Correspondence: gjoshi@mines.edu

\begin{abstract}
One of the most critical challenges for modern power systems is to reliably supply electricity to its consumers during and in the aftermath of natural disasters. As our dependence on electrical power has increased over the years, long-term power outages can lead to devastating impacts on affected communities. Furthermore, power outages can halt the operation of water treatment plants, leading to shortages in clean water, which is essential during post-disaster recovery. One way to address this is to temporarily reconfigure power and water networks into localized networks, i.e., electric microgrids and water micro-nets, that utilize local resources to supply local demand independently of the main power grid and/or water network. Utilizing distributed energy resources such as wind and solar and treating wastewater locally for potable reuse can provide the operational flexibility for such systems to operate sustainably. However, due to uncertainties in both renewable energy generation and electric/water consumption, ensuring sustainable operation is a challenging task. In this paper, an optimal operational strategy is proposed for an islanded microgrid/micro-net, considering the stochastic nature of renewable energy resources, electric demand, and water demand. An energy storage system is modeled to address the uncertainty in power generation and demand, in conjunction with local water storage and wastewater treatment to accommodate variable water demands. A two-stage stochastic programming model is formulated and solved to determine an optimal operation strategy for the combined system.
\end{abstract}

Keywords: energy optimization; demand response; electric microgrid; natural disasters; power system resilience; water micro-net

\section{Introduction}

The electric power grid has evolved from historical one-way power networks where a single generation unit served a small number of predictable loads, to modern-day power systems, which form the largest running machine ever built by humans, spanning thousands of miles and connecting millions of components [1,2]. The modern power system is not only expanding in size but is also becoming more complex due to increasing penetration of variable energy resources, energy storage systems, electric vehicles, and variable power electronic-controlled loads [3]. As more aspects of our daily lives depend on electricity, access to reliable power is becoming the cornerstone of modern society. Electrical power is essential for running telecommunication systems, transportation systems, pumping stations in metropolitan water distribution systems, water treatment and wastewater management facilities, machines used for food processing and storage, and heating and cooling of buildings, to name a few. Recently, this was further underlined by the Uri winter storm in the state of Texas in February 2021 [4,5]. During the event, the Electric Reliability Council of Texas (ERCOT) had to order transmission service providers (TSPs) and distribution service providers (DSPs) to perform rolling power outages across their territories to prevent a statewide blackout. There are many examples that show the vulnerability of the power grid to natural disasters and manmade disturbances [6-8].

In addition to damages to the economy and the environment, most natural disasters result in significant social impacts, especially on socially vulnerable groups. For example, 
people with compromised health conditions or lower incomes may not be able to evacuate to safety as easily as those who are healthy and more affluent $[9,10]$. Furthermore, people of lower socioeconomic status are more likely to live in homes that are more vulnerable to natural disasters, which could in turn result in more dire consequences [11,12]. It is clear that in order to improve a community's responsiveness to or preparedness against large-scale disturbances, one must develop contingency plans and organize resources to reduce post-disturbance impacts on people's health and livelihoods $[13,14]$.

Although various reinforcement strategies can in theory be adopted to protect the grid against such events, most are either not efficient or cost prohibitive. This is in part due to the severity of the events, which are on the rise thanks to climate change [15-17], but also due to the lack of accurate mathematical models that can predict their timing and/or geographical scope with reasonable accuracy. As such, adaptive resilience solutions are needed to allow for more flexible operation during and in the aftermath of a natural disaster. One such solution is the concept of the electric microgrid. This is a small-scale power system that is equipped with distributed energy resources and controllable loads and has the capability to island from the grid and support its load locally upon need. Microgrids can significantly enhance the reliability of the power system by providing continued support during outages. Many microgrids rely on renewable energy generation such as rooftop PV systems and/or small-scale wind turbines. Due to their intermittent and stochastic nature, renewable energy resources pose operational challenges in microgrids. First, the small number of energy resources means that volatility in one would have a higher overall impact on the overall network. Furthermore, there are likely less reserves available to counteract their variability. These issues can of course be mitigated by using energy storage systems, e.g., community energy storage (CES), in conjunction with variable resources $[18,19]$. A similar concept has been proposed in the literature for extension to water distribution networks, where the original water distribution and supply network is broken into smaller-scale sections known as micro-nets [20,21].

As the concept of microgrids and micro-nets are critical to maintain the resiliency of energy and water systems, many researchers have discussed how future communities should be designed and planned so that individual neighborhoods can be better prepared for potential disturbances to the system [22,23]. Operating such a system requires simultaneous management of both energy and water resources. However, additional challenges are introduced due to interconnection between the two networks, especially the dependence of the water network on the power system. As such, a co-optimization strategy is needed to model both systems within a single framework.

In recent years, the electrical power system has seen increased penetration levels of renewables into the network at both the transmission and distribution levels. This trend is driven by environmental, economic, and energy security drivers, as well as concerns over the long-term availability of fossil fuels and conventional technologies [24,25]. It is expected that the future of the power system will be in the form of an interconnected network of small-scale and self-contained microgrids supported by a large-scale bulk energy system [26]. The skeleton of the grid will then be used to provide connectivity among these localized microgrids. As the microgrids serve critical loads such as the water system, it is important to maintain connectivity between power and water networks for resilient operation for the community during a natural disaster. In recent years, researchers have investigated combining water systems with power systems in such a way that the need for energy in the water system can be supplied using renewable generators, and flexibility in water systems can be harnessed to better plan for the energy needs of communities [27-30]. For instance, authors in [31] proposed a microgrid system that operated using a wind turbine, solar PV, battery system and a pump that could also operate as a turbine and generate electricity. Authors in [32] proposed a solution to utilize water pumps and water tanks in order to absorb the surplus electrical energy from renewable energy resources. Coordinating with a wastewater treatment plant (WWTP), the water distribution system provides flexibility in operating either the plant or the related water pumps whenever 
there is sufficient generation available from wind and PV systems, which are otherwise turned off when there is higher electrical demand in the system [33,34]. Clean water from the WWTP can be pumped from lower elevations to higher elevations and stored in water distribution tanks at times of high generation. Once the tanks are filled to a desired height, gravitational force can be utilized to supply water demand to customers with little or no energy consumption.

In order to provide a reliable supply of energy in the system, CES is often considered in conjunction with wind and PV systems [35]. Although CES can help improve the quality of power, its overall cost is significant compared to the zero fuel cost of renewable generators [36]. Another way to mitigate the variability of renewables is to use demand response (DR) [37]. With DR, loads can be controlled (shed or shifted to a different time) such that power generation matches the power demand at any given time. Similarly, there are pump-scheduling techniques proposed in the literature to reduce their energy footprint [38,39]. Many researchers have focused on the operation of microgrids with stochastic energy resources [40]; authors in [41] developed a two-stage stochastic model to estimate a day-ahead optimal strategy for dispatching distributed units, considering the variability of renewable energy resources. Similarly, authors in $[42,43]$ formulated a two-stage stochastic programming problem to incorporate uncertainty in load and PV forecasts. Authors in [43] developed a stochastic mixed-integer programming model to identify the optimal size of power system components considering variability in wind and PV systems.

This paper presents a coordinated water and energy operation strategy in an isolated community, operating as a combined microgrid/micro-net. It has been assumed that the community is either geographically far away from the main grid or is no longer connected to it due to some disturbances causing an outage. It is shown how limited energy and water resources can be optimally allocated to address the needs of the community. To address uncertainties in generation and demand, a stochastic framework is considered. To do this, a two-stage stochastic programming formulation has been proposed which ensures that the demands (both water and power) are met as much as possible, at minimum cost, and with a minimum amount of load shedding or shifting. In the first stage of the problem, the solution determines the amount of water to be purchased from the external source at the start of the dispatch period (e.g., a day in advance) and the amount of energy purchased to charge the battery. It is assumed that the community is equipped with a water storage tank and a CES. Then, during the second stage, the purchased resources are utilized to address demands, while considering the expected probabilities of uncertainties in power generation, water demand, and power demand. Furthermore, load shedding and shifting decisions are considered to assist with dispatch.

The rest of the paper is as follows: A system description is presented in Section 2, followed by the scope of study and contribution of the work in Section 3. Problem formulation is presented in Section 4. A case study is discussed in Section 5 for proof-of-concept purposes, along with future work in Section 6. Finally, the concluding remarks are presented in Section 7 of the paper.

\section{System Description}

This paper considers a self-reliant community, which tries to limit external help for its water and energy needs. In other words, the community tries to optimize the use of locally available energy and water resources in order to be resilient against any disturbances in the system. Without loss of generality, the neighborhood is assumed to consist of multiple residential water and energy users connected to a single power distribution bus and water distribution network as shown in Figure 1. Furthermore, it is assumed here that:

- The microgrid consists of an energy storage system (a battery in this case), a smallscale wind turbine, and rooftop PV systems for individual residential units. These generation units have uncertainties as discussed below. The choice of energy resources 
does not affect the generality of the problem; however, it is intended to show the impacts of uncertainties in available energy.

- Similarly in the water distribution network, a storage tank (ST) is installed to supply water demand of the community.

- The ST receives water through two means: water purchased and delivered by water tankers (or perhaps coming from the main water distribution network), or treated potable water provided by the local WWTP.

- The geographical area served by the water and energy networks is small and power losses in power distribution lines and water losses in the water system can be ignored safely.

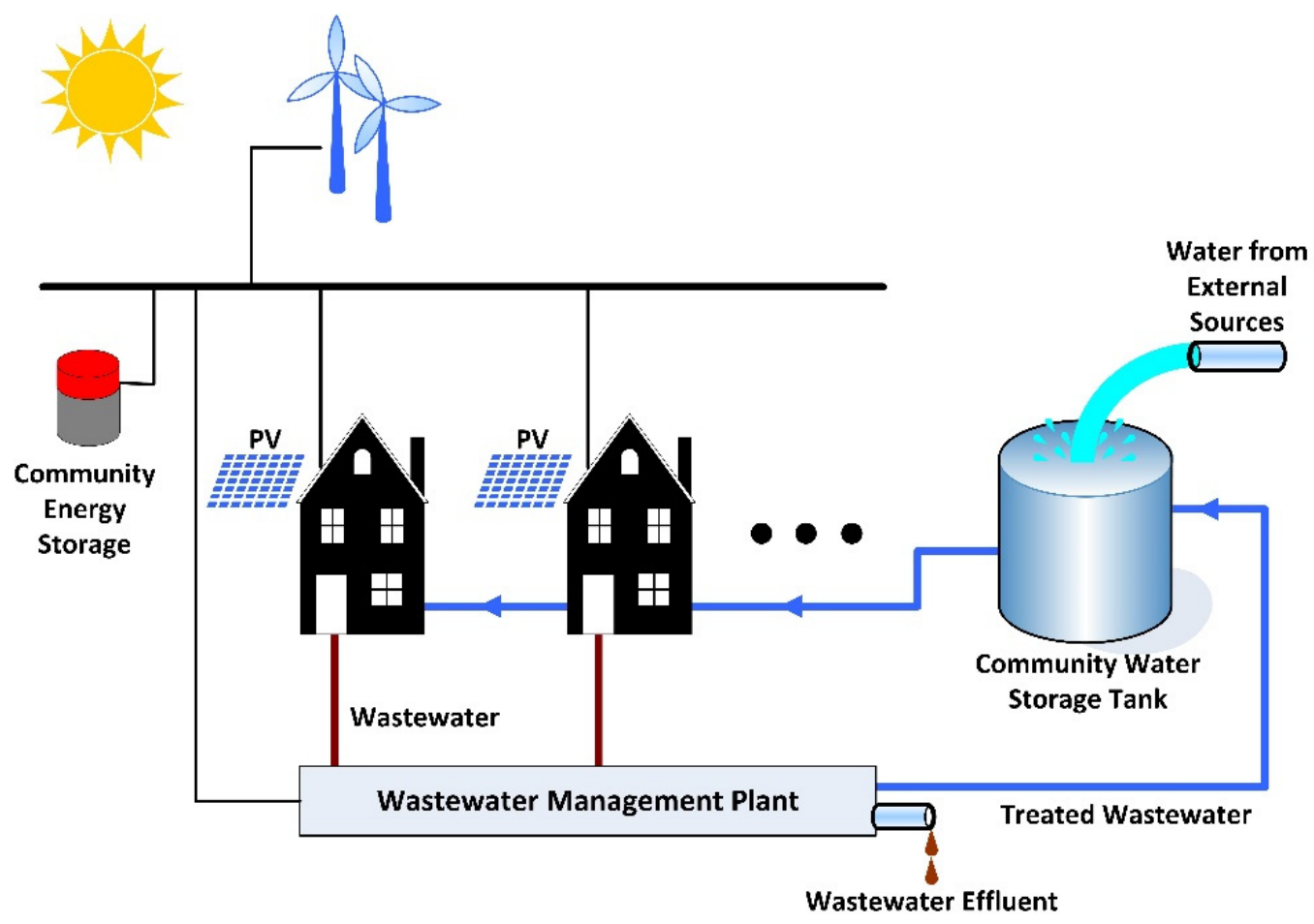

Figure 1. Energy and water flow diagram of the community under study. This schematic diagram shows how the energy generators and loads are connected to a microgrid bus. A ST receives water from external sources and supplies water to the community. Wastewater from households is treated in a WWTP and clean water is pumped into ST for reuse.

The residential customers are at a lower elevation than the elevation of the community ST, which means that water can be supplied to the households naturally due to gravity, which saves energy usage on pumping systems that would otherwise be needed. Similarly, the WWTP is located at a lower elevation than the individual households so that the wastewater from households can flow to the WWTP naturally without a need for pumping. However, the treated clean water needs to be pumped to the ST, and the WWTP treats the incoming batch of the wastewater over a $2 \mathrm{~h}$ time period.

This paper presents a stochastic optimization model that optimizes the combined operation of the integrated microgrid/micro-net system, considering the uncertainties associated with power generation, power demand, and water demand.

In order to model the uncertainties, a scenario-based approach is utilized in this paper. This is adopted because it considers the system uncertainties as random input variables and assigns probabilities to each scenario based on data observations [44]. Without loss of generality, four uncertain parameters are considered, i.e., power demand, water demand, wind power generation, and PV power generation, each one having two levels of low and high values for each time-step to represent hourly variations. These levels could 
occur based on factors such as the time of day and/or occupancy of individual residential units. For a $t$ number of time-steps and $l$ number of levels, the total number of scenarios for $m$ number of uncertain parameters is $l^{t \cdot m}$. This has been conceptually shown for two uncertain parameters, $\mathrm{X}$ and $\mathrm{Y}$, with two levels of uncertainty, $\mathrm{H}$ and $\mathrm{L}$, for each, over a total of two timesteps-resulting in a combined total of 16 scenarios as indicated in Table 1. Each level $\mathrm{H}$ or $\mathrm{L}$ has its corresponding probability of occurrence which can be estimated using historical data. As the number of uncertain parameters or time-steps increases, the total number of scenarios will increase exponentially, resulting in an exponential rise in computational time [45]. This indicates that in order to solve the stochastic model with a large number of time-steps or uncertain parameters, scenario reduction techniques may be necessary [46,47].

Table 1. Scenario table for uncertain parameters. $\mathrm{L}=\mathrm{Low}, \mathrm{H}=$ High.

\begin{tabular}{cccccc}
\hline \multirow{2}{*}{ Scenario } & & Time 1 & & Time 2 & Probability \\
\cline { 2 - 6 } & $\mathbf{X}$ & $\mathbf{Y}$ & $\mathbf{X}$ & $\mathbf{Y}$ & $\mathbf{P}$ \\
\hline 1 & & & $\mathrm{H}$ & $\mathrm{H}$ & $\mathrm{P} 1$ \\
2 & & $\mathrm{H}$ & & $\mathrm{L}$ & $\mathrm{P} 2$ \\
3 & & & $\mathrm{~L}$ & $\mathrm{H}$ & $\mathrm{P} 3$ \\
4 & $\mathrm{H}$ & & $\mathrm{L}$ & $\mathrm{P} 4$ \\
5 & & & $\mathrm{H}$ & $\mathrm{H}$ & $\mathrm{P} 5$ \\
6 & & $\mathrm{~L}$ & & $\mathrm{~L}$ & $\mathrm{P} 6$ \\
7 & & & $\mathrm{~L}$ & $\mathrm{H}$ & $\mathrm{P}$ \\
8 & & & $\mathrm{H}$ & $\mathrm{H}$ & $\mathrm{P}$ \\
9 & & $\mathrm{H}$ & & $\mathrm{L}$ & $\mathrm{P} 10$ \\
10 & & & $\mathrm{~L}$ & $\mathrm{H}$ & $\mathrm{P} 11$ \\
11 & & & & $\mathrm{~L}$ & $\mathrm{P} 12$ \\
12 & $\mathrm{~L}$ & & $\mathrm{H}$ & $\mathrm{H}$ & $\mathrm{P} 13$ \\
13 & & & & $\mathrm{H}$ & $\mathrm{P} 14$ \\
14 & & $\mathrm{~L}$ & $\mathrm{~L}$ & $\mathrm{~L}$ & $\mathrm{P} 16$ \\
15 & & & & & \\
16 & & & &
\end{tabular}

The scenario-reduction method, however, reduces the accuracy in calculating the actual solution as it eliminates scenarios to decrease computational time. In this paper, a sliding window approach is presented by considering a smaller number of time-steps that would significantly reduce the total number of scenarios to be computed at once. Hence, at each point in time, the proposed SP model is solved over a three-hour window to determine decision variables such as the battery SOC, the amount of loads shed/shift, and the volume of water in ST. This approach will provide a total of 4096 scenarios that are incorporated into the SP model. It should be noted that these scenarios are chosen for proof-of-concept purposes and do not affect the generality of the proposed methodology. Higher number of scenarios will improve the accuracy of the model, at the expense of the simulation time.

\section{Scope and Contribution of Work}

This paper considers the quasi-steady-state operation of a microgrid and devises a strategy to maintain power balance under uncertainties. This is to ensure frequency stability in the microgrid under various operating conditions. It has been assumed in this paper that energy resources (PV, wind, and CES) are equipped with necessary local control systems to be able to operate in an islanded mode and generate the desired level of active power. As such, this aspect is considered outside the scope of the current study.

The contributions of the paper can be outlined as below:

(1) Although numerous papers in the literature have addressed the problem of optimal control and energy dispatch of electric microgrids, this paper focuses on the co-optimization model, where both power, water, and wastewater networks are con- 
sidered, along with interconnections between the three; this aspect is less explored in the literature.

(2) The proposed methodology ensures that the water distribution system, which is critical for post-disaster recovery, remains operational and available.

(3) This research provides a case for investing distributed community-scale water and energy technologies, for instance, distributed wastewater treatment, rather than fully centralized approaches, which could provide a single point of failure during major disturbances.

(4) Furthermore, this research demonstrates that the flexibility of a small-scale local water distribution network can be harnessed to balance load-generation in a microgrid with renewable energy resources.

\section{Problem Formulation}

The main goal in this paper is to propose a strategy to minimize the overall cost of meeting water and power demands over the dispatch period, while minimizing load shedding, given uncertainties in both water and power consumption. The problem is formulated in the form of a two-stage stochastic optimization: The first-stage variables are assumed to be the amount of water to be purchased from an external resource and the amount of power to charge the battery before the dispatch period begins. The second-stage variables consist of the dispatch (charge/discharge) schedule of the battery, operation schedule of the wastewater treatment plant, and the amount of load shift or shed for individual users during each scenario.

\subsection{Objective Function}

The objective function is shown in (1). The first two terms indicate the costs of purchasing water to store in the storage tank and power to charge the battery. These are the first-stage variables. The next term, weighed by the probabilities of individual scenarios, indicates the cost of discharging the battery as well as the penalties associated with load shedding. The number of deep discharge cycles available in a battery limits the lifetime of the battery and it is modeled in terms of cost per deep discharge of the battery. The optimization model tries to minimize the power obtained from battery discharge. The discharging amount would change as the likely scenarios for power generation and demand change. This has been modeled as a cost function in (1). The fourth term in the objective function is used to ensure that individual power demands are supplied at the desired time and desired $\mathrm{kW}$ level as much as possible for each scenario. Here, when a shiftable load at time $t$ and scenario $s$ is served at the intended time, its corresponding binary variable will be 1 (i.e., $v_{i, t, t, s}=1$ ), which indicates that the load will not be shed or shifted to a future time-step and that there will be no penalty cost. Otherwise, any load shed or shift (i.e., when $v_{i, t, t, s}=0$ ) introduces a penalty into the objective function, which is weighed by the occupancy level of the house.

The cost-based approach in this formulation can be viewed in the form of penalties associated with each objective function. For instance, the cost function for the battery discourages battery usage when wind and PV systems generate power. This is to prolong the life of the battery by minimizing the number of its charge/discharge cycles. Similarly, purchasing power from grids or water from an external source is discouraged using the cost (penalty) in the objective function. The big $M$ represents a large number and is intended to, whenever technically possible, discourage load shedding in the microgrid. This is because supplying as many customers as possible is more important than the actual cost of dispatch, as is the case in any emergency dispatch strategy.

$$
\min \left[c^{w} \cdot V^{\mathrm{ST}, \mathrm{in}}+c^{u} \cdot P^{u}+\sum_{s \in S} p_{s} \cdot\left\{\sum_{t \in \mathrm{T}} c^{b} \frac{P_{t, s}^{b, d}}{P^{b, \mathrm{max}}}+M \cdot \sum_{i \in \mathrm{N}} \sum_{k \in \mathrm{T}} o_{i, t, s} \cdot\left(1-v_{i, t, k, s}\right)\right\}\right]
$$




\subsection{Constraints}

The multi-objective optimization problem in (1) is solved subject to the following constraints. It is assumed in this formulation that there will be no revenue from water distribution because water will be supplied to meet minimum demand without any cost to the users. Furthermore, the pump operating cost is included in the battery discharging cost.

\subsubsection{Power Balance}

At each time-step and for each scenario, the total amount of power provided by the generation resources must equal the total demand, as given in (2). Power generation from wind and PV resources depends on wind velocity and solar irradiance, respectively. This means that the power generation level may change under different scenarios. Similarly, power demand and water demand may change according to different considered scenarios, as modeled in (3). Since the power demand in the micro-grid is an uncertain parameter for a given time, it is divided among all customers connected to the grid using contribution factors as given in (4). These contribution factors can be estimated based on historical demand profiles. This approach helps reduce the total number of scenarios to be considered for power demand. Equation (5) estimates the contribution of shiftable and non-shiftable loads to the total power demand of a customer. In this formulation, the electrical power losses in the microgrid have been ignored because of the small geographical span of the power distribution network. However, for a larger distribution network that consist of longer distribution lines, the power loss can be easily incorporated into the formulation.

$$
\begin{gathered}
\forall t \in \mathrm{T}, \forall s \in S: P_{t, s}^{w}+P_{t, s}^{b, d}-P_{t, s}^{b, c}=\sum_{i \in \mathrm{N}}\left(P_{i, t, s}^{d}-P_{i, t, s}^{\mathrm{PV}}\right)+P_{t, s}^{w w} \\
\forall i \in \mathrm{N}, \forall t \in \mathrm{T}, \forall s \in S: P_{i, t, s}^{d}=P_{i, t, s}^{\mathrm{d}, \mathrm{NSH}}+\sum_{k=1}^{t} v_{i, k, t, s} \cdot P_{i, k, s}^{\mathrm{d}, \mathrm{SH}} \\
\forall i \in \mathrm{N}, \forall t \in \mathrm{T}, \forall s \in S: P_{i, t, s}^{d, \mathrm{NSH}}=d_{i} \cdot P_{i, t, s}^{d} \\
\forall i \in \mathrm{N}, \forall t \in \mathrm{T}, \forall s \in S: P_{i, t, s}^{d}=P_{t, s}^{d} \cdot D_{i}
\end{gathered}
$$

\subsubsection{Demand Response (Load Shifting and Load Shedding)}

Demand shifting is a form of demand response, in which a certain portion of demand is shifted to a future time. The amount of demand-shifting should be regulated as it can cause inconvenience for customers. As given in Equation (6), a shiftable load can only be shifted to one future time-step, and not multiple time-steps. The load may be shed instead of being shifted to a future time-step as given by the inequality sign in Equation (6). Load shedding is another form of demand response used in this paper. It is assumed here that demand shifting is not performed partially and, if scheduled, the entire load will be shifted to a future time-step. The constraint (7) limits the number of times a customer may experience demand shifting during the dispatch period. It should be noted that for a shiftable load, $v_{i, t, t, s}=1$ indicates that the load will be supplied at time $t$ as intended during scenario $s$, and it will not be shifted to a future time-step.

$$
\begin{aligned}
& \forall i \in \mathrm{N}, \forall k \in \mathrm{T}, \forall s \in S: \sum_{t=k}^{\mathrm{T}} v_{i, k, t, s} \leq 1 \\
& \forall i \in \mathrm{N}, \forall s \in S: \sum_{t=1}^{\mathrm{T}} v_{i, t, t, s} \geq \mathrm{T}-\mathrm{TSH}
\end{aligned}
$$

\subsubsection{Battery Constraints}

For a given time $t$ and scenario $s$, the battery can be either charging or discharging, but not both (see (8)). Also, the constraints for the state-of-charge (SOC) of the battery 
are represented by (9) and (10). Without loss of generality, it is assumed that prior to the dispatch period, the battery had been left depleted. It is possible to raise the charge on the battery prior to the start of the dispatch period by purchasing power from a utility. The amount of power to be purchased is a first-stage variable, which is determined based on the severity and likelihood of different scenarios. For future time-steps, battery SOC will be determined based on the level at which it is charged or discharged, as well as a self-discharge rate. For any time-step and any scenario, the SOC must remain between the maximum and minimum acceptable limits, as indicated in (8).

$$
\begin{gathered}
\forall t \in \mathrm{T}, \forall s \in S: u_{t, s}^{b, c}+u_{t, s}^{b, d} \leq 1 \\
\forall s \in S: S O C_{0, s}=S O C^{\min }+\frac{P^{u} \cdot \eta^{c}}{P^{\mathrm{B}, \max }} \leq S O C^{\max } \\
\forall t \in \mathrm{T}, \forall s \in S: S O C_{t, s}=(1-\gamma) \cdot S O C_{s, t-1}+\frac{P_{t, s}^{b, c} \eta^{c}}{P^{b, \max }}-\frac{P_{t, s}^{b, d}}{\eta^{d} P^{b, \max }} \\
\forall t \in \mathrm{T}, \forall s \in S: S O C^{\min } \leq S O C_{t, s} \leq S O C^{\max }
\end{gathered}
$$

\subsubsection{Power Generation Constraints}

Power generated by wind turbines and PV panels for time $t$ during scenario $s$ depends on the available wind speed and solar irradiance, respectively (see (11)). The wind speed and solar irradiance vary randomly based on the scenarios in Section 2, which will then be used to determine the power generated by each resource. It is assumed here that the same amount of solar irradiance is available for all PV units since the geographical area of the microgrid is small. The input and output $\mathrm{kW}$ from the battery system is limited by its maximum power for each time and scenario, as given in (12).

$$
\begin{gathered}
\forall t \in \mathrm{T}, \forall s \in S: P_{t, s}^{\mathrm{Wind}}=\frac{0.5 \cdot \alpha \cdot \rho_{a} \cdot A \cdot\left(w_{t, s}\right)^{3}}{1000} \\
\forall i \in \mathrm{N}, \forall t \in \mathrm{T}, \forall s \in S: P_{i, t, s}^{\mathrm{PV}}=P_{i}^{\mathrm{PV}, \mathrm{STC}} \frac{\Phi_{t, s}}{\Phi^{\mathrm{STC}}} \\
\forall t \in \mathrm{T}, \forall s \in S:\left\{\begin{array}{l}
0 \leq P_{t, s}^{b, d} \leq P^{b, \max } u_{t, s}^{b, d} \\
0 \leq P_{t, s}^{b, c} \leq P^{b, \max } u_{t, s}^{b, c}
\end{array}\right.
\end{gathered}
$$

\subsubsection{Water Demand Constraints}

For each scenario, the total amount of water flow provided by the storage tank to the community should equal the total water demand, which is a sum of individual customers' water demands. At the beginning of the dispatch period, it has been assumed that the tank had been filled to the minimum level, and the neighborhood has the option of purchasing water from an external resource prior to the realization of various scenarios as given in (14). The amount of purchased water is a first-stage variable. This water purchase from external sources may be necessary because the WWTP is assumed to take at least $2 \mathrm{~h}$ to treat the water obtained from the residential neighborhood, as given by zero outflow from WWTP in (15) during time-steps 1 and 2. The volume of water in the ST is computed using the inflow and outflow rates of water in the ST (see (16)). Total volume of water in the ST should be within the acceptable range indicated in (17).

$$
\begin{gathered}
\forall t \in \mathrm{T}, \forall s \in S: \sum_{i \in \mathrm{N}} q_{i, t, s}^{d}=q_{t, s}^{\mathrm{ST}, \text { out }}=Q_{t, s}^{d} \\
\forall s \in S: V_{0, s}^{\mathrm{ST}}=V^{\mathrm{ST}, \text { in }} \\
\forall s \in S: q_{1, s}^{\mathrm{ww}, \mathrm{out}}=q_{2, s}^{\mathrm{ww}, \mathrm{out}}=0 \\
\forall t \in \mathrm{T}, \forall s \in S: V_{t, s}^{\mathrm{ST}}=V_{t-1, s}^{\mathrm{ST}}+q_{t, s}^{\mathrm{ww}, \text { out }} \cdot \Delta-q_{t, s}^{\mathrm{ST}, \text { out }} \cdot \Delta \\
\forall t \in \mathrm{T}, \forall s \in S: V^{\mathrm{ST}, \mathrm{min}} \leq V_{t, s}^{\mathrm{ST}} \leq V^{\mathrm{ST}, \mathrm{max}}
\end{gathered}
$$




\subsubsection{Wastewater Management Constraints}

A certain fraction of water discharged from the customer collects at the WWTP to be treated (see (18)). Considering the hourly timeline of this problem formulation, this has been considered to occur at the same time-step $t$. Flow through pipes is limited by the maximum allowable rate, as indicated in (19). The volume of water in the WWTP is computed using the inflow and outflow rates of water in the WWTP (see (20)). There is a minimum and maximum allowable range for the water volume in the WWTP which should be maintained at all times for each scenario, as shown in (21). Finally, the amount of water treated in the WWTP and pumped into the ST determines the total power consumption in the wastewater treatment system. In this formulation, the volume of water treated and pumped back to the ST is assumed to be proportional to the power consumption in the WWTP and pumping system, as shown in (22). Constraint (23) ensures that there is no waste outflow during the first two hours of the study period because the WWTP will take $2 \mathrm{~h}$ for treatment.

$$
\begin{gathered}
\forall t \in \mathrm{T}, \forall s \in S: \sum_{i \in \mathrm{N}} q_{i, t, s}^{d}=k^{w w} \cdot q_{t, s}^{w w w, \text { in }} \\
\forall i \in \mathrm{N}, \forall t \in \mathrm{T}, \forall s \in S: q_{i, t, s}^{d} \leq q^{\max } \\
\forall t>1, \forall s \in S: V_{t, s}^{w w w}=V_{t-1, s}^{w w}+q_{t, s}^{w w w, \text { in }} \cdot \Delta-q_{t, s}^{w w w, \text { out }} \cdot \Delta-q_{t, s}^{w w w, \text { eff }} \cdot \Delta \\
\forall t \in \mathrm{T}, \forall s \in S: V^{w w, \text { min }} \leq V_{t, s}^{w w w} \leq V^{w w, \text { max }} \\
\forall t \in \mathrm{T}: P_{t, s}^{w w}=\left(p^{w w w}+p^{\text {pump }}\right) \cdot q_{t, s}^{w w \text { out }} \cdot \Delta \\
\forall s \in S: q_{1, s}^{w w w, \text { eff }}=q_{2, s}^{w w w \text { eff }}=0
\end{gathered}
$$

\section{Case Study}

\subsection{Solution Methodology and Input Data}

A hypothetical electrical microgrid is considered as the case study in this paper that consists of three residential units. As discussed in Section 2, four uncertain parameters are considered, i.e., wind power generation, PV power generation, total electrical demand in the network, and water demand in the water distribution system. Each of these parameters are assumed to have a high and a low level and to change on an hourly basis. Data for wind and PV power generation and the energy demands of the customers are estimated using the data available from the US Department of Energy, National Renewable Energy Laboratory, National Solar Radiation, and Residential Energy Consumption Survey, as explained in [48]. Similarly, household occupancy is estimated based on the data provided in the same paper. The water demand for customers is modeled considering the estimated data provided by the U.S. Geological Survey (USGS) in [49], which indicates that on average each person uses about 100 gallons of water per day on the higher end. This paper accounts for the occupancy levels of households to estimate total water use per household per day. It should be noted that the values of all input parameters are chosen for demonstration purposes only and as such, they do not affect the generality of the problem. Further, it is assumed that each household consists of a combination of shiftable and non-shiftable loads as given in Table 2. It is assumed that approximately $60 \%$ of energy demand is for non-shiftable loads and $40 \%$ for shiftable loads. Table 2 provides energy per day for a typical single-family household adopted from EIA data [50].

Table 2. Energy consumption of a single-family household per day.

\begin{tabular}{cccc}
\hline Non-Shiftable Loads & kWh & Shiftable Loads & kWh \\
\hline $\begin{array}{c}\text { General lighting loads, cooking stove, } \\
\text { oven, microwave, and refrigerator }\end{array}$ & 18 & $\begin{array}{c}\text { Dishwasher, laundry machine and dryer, } \\
\text { TV, and other non-essential electronics }\end{array}$ & 12 \\
\hline
\end{tabular}


The data in Table 2 is based on an average $30 \mathrm{kWh}$ of energy usage per day for a single-family household (877 kWh per month) with two occupants. Some of the nonshiftable loads considered in this study are, for example, power demand due to general lighting, refrigerators, and cooking stoves and microwaves, since their interruption could lead to inconvenience. This accounts for $60 \%$ of total household energy consumption. However, other appliances such as TVs and other large electronics, washers and dryers, and dishwashers are considered to be shiftable, since their operation times can be changed without significantly impacting residents. This accounts for $40 \%$ of total household energy consumption. Since household occupancy affects the energy consumption of both shiftable and non-shiftable loads, different occupancy profiles (ranging from one occupant to five occupants) have been considered for the customers in the community in order to introduce diversity in energy consumption of the houses. It is assumed that the maximum allowable number of times during the study period that a customer may experience demand shifting (or TSH) is 1 . For the data on $\Phi^{\mathrm{STC}}, \alpha, S O C^{\min } / S O C^{\max }, \gamma, \mathrm{c}^{\mathrm{B}}$, and $\eta^{c} / \eta^{d}$ readers are referred to [51]. A single wind turbine is considered for this study, with a diameter of approximately $7 \mathrm{~m}\left(200 \mathrm{~m}^{2}\right.$ swept area). The air density $\rho_{a}$ is assumed to be $1.25 \mathrm{~kg} / \mathrm{m}^{3} . P_{i}^{\mathrm{PV}, \mathrm{STC}}$ values of $5 \mathrm{~kW}$ to $10 \mathrm{~kW}$ in each house have been assigned to reflect the PV generation of each customer [52]. The CES is considered to be sized at $140 \mathrm{~kW}$. The water distribution system is assumed to already be installed and ready to be operated in the community. The maximum flow per house is $0.0001262 \mathrm{~m}^{3} / \mathrm{s}$ (2.0 gallons per minute (GPM)) at approximately 60 pound per square inch (PSI) of pressure (or $414 \mathrm{kPa)}$ ), as recommended in [53].

The proposed optimization formulation is solved using General Algebraic Modeling System (GAMS) software developed by GAMS Development Corp, Fairfax VA, USA in an Intel ${ }^{\circledR}$ Core $^{\mathrm{TM}} \mathrm{i} 7-8750 \mathrm{H}$ CPU @ $2.5 \mathrm{GHz}-2.21 \mathrm{GHz}$ computer. As expected, the solution time increases with increases in the number of scenarios. Two cases have been considered: The first case (case 1) considers two time-steps of analysis, and hence a total of 256 different scenarios (four variables, at two levels each, over two timesteps). The second case (case 2) considers three time-steps instead, raising the total number of scenarios to 4096. The solution time for case 2 is $607 \mathrm{~s}$ ( $10 \mathrm{~min})$, which is significantly higher than that of case 1 at less than $2 \mathrm{~s}$.

\subsection{Results and Discussion}

Table 3 lists the results of the analysis for both cases. For case 1, the community would need to purchase $12.92 \mathrm{kWh}$ of electrical energy at the beginning of the study period in order to meet the energy needs for the next $2 \mathrm{~h}$ (i.e., the duration of the study period). Similarly, $6.48 \mathrm{~m}^{3}$ of water is necessary to properly meet the water needs of customers. The CES would need to supply $19.48 \mathrm{kWh}$ of electricity at a cost of $\$ 13.88$. On average, it would cost approximately $\$ 10.83$ per hour for the community to meet their energy and water needs. Considering the dispatch over a $3 \mathrm{~h}$ period, $3 \mathrm{kWh}$ of electricity and $6.48 \mathrm{~m}^{3}$ of water are needed from external sources in order to meet the energy and water needs. In this case, the CES would need to supply a total of $19.94 \mathrm{kWh}$ to account for insufficient generation from wind and PV systems. This would cost approximately $\$ 7$ per hour. It is important to note that having more information about the future may support the decision process for the system operator, since more possible scenarios are considered. However, generally speaking, it does not indicate that more information will guarantee a more favorable (i.e., less expensive) solution. 
Table 3. Solution of the proposed co-optimization problem.

\begin{tabular}{|c|c|c|c|c|}
\hline \multirow{2}{*}{$\begin{array}{c}\text { Case } \\
\text { Objective Function }\end{array}$} & \multicolumn{2}{|c|}{ Case 1 (2 Time-Steps) } & \multicolumn{2}{|c|}{ Case 2 (3 Time-Steps) } \\
\hline & Value & Cost (\$) & Value & Cost (\$) \\
\hline $\begin{array}{l}\text { Power purchased from utility } \\
\qquad(\mathrm{kWh})\end{array}$ & 12.92 & 1.29 & 3.01 & 0.30 \\
\hline Water purchased $\left(\mathrm{m}^{3}\right)$ & 6.48 & 6.48 & 6.48 & 6.48 \\
\hline Average battery operation (kWh) & 19.48 & 13.88 & 19.94 & 14.20 \\
\hline Total cost $(\$)$ & \multicolumn{2}{|c|}{21.65} & \multicolumn{2}{|c|}{20.98} \\
\hline $\begin{array}{c}\text { Probability of load shedding or } \\
\text { shifting on average * }\end{array}$ & \multicolumn{2}{|c|}{$0.68 \%$} & \multicolumn{2}{|c|}{$0.043 \%$} \\
\hline Total cost per hour $(\$)$ & \multicolumn{2}{|c|}{10.83} & \multicolumn{2}{|c|}{6.99} \\
\hline
\end{tabular}

* The average probability of demand response represents how likely it is for any customer to see either load shedding or shifting considering the probability of different scenarios for power generation and demand. A $0 \%$ value indicates that the microgrid has sufficient power generation to meet the demand for all possible scenarios considered in the study.

The following sections further discuss the results of the case studies for three strategically chosen scenarios. While the overall results are summarized in Table 3, these three individual scenarios are provided for demonstration purposes, and in general do not have any uniqueness over other scenarios modeled. Instead, they represent the overall pattern in the output of the formulation as the uncertain parameters change their values.

The following scenarios are compared to demonstrate the results of case 2:

- Scenario 1: This scenario represents operating conditions during which power generation is less than power demand in the microgrid with high water demand.

- Scenario 2: This scenario represents operating conditions during which power generation is more than power demand in the microgrid with low water demand.

- Scenario 3: This scenario represents operating conditions during which power generation and demand in the microgrid are close in value with average water demand.

Figure 2 shows the power generation level from different sources (wind, PV, and battery discharging) and the power demand (household energy demand, WWTP power demand, and battery charging) for each time-step. During scenario 1 , there is approximately $46 \mathrm{~kW}$ of demand during time-step 3 in the microgrid, which is being supplied from the primary generation sources of wind $(26 \mathrm{~kW})$ and PV systems $(20 \mathrm{~kW})$. Because generation is sufficient to supply the entire demand, the battery is neither charging nor discharging (also shown by the constant SOC level in Figure 3 for scenario 1 time-step 3). On the other hand, for time-step 2 during scenario 1, the CES is discharging at a rate of approximately $45 \mathrm{~kW}$, because during that time, the total demand (approximately $103 \mathrm{~kW}$ ) is more than the power generated by primary sources (approximately $58 \mathrm{~kW}$ from wind and PV). Similarly, during time-step 1 of scenario 1, the CES is discharging at a rate of $25 \mathrm{~kW}$. For scenario 2, during which power generation is more than the demand, the battery is charging at rates of approximately $4 \mathrm{~kW}$ and $13 \mathrm{~kW}$ at time-steps 1 and 3, respectively. This way, the stored energy can be utilized when needed. During scenario 3 , the total generated power from wind and PV systems is close to the power demand in time-steps 1 and 2, but not completely enough to meet the entire demand. Hence, CES discharges at a lower rate of $4 \mathrm{~kW}$ in both times compared to scenario 1 . The primary sources meet the power demand during time-step 3, which means the CES system is offline, as shown in the graph. 

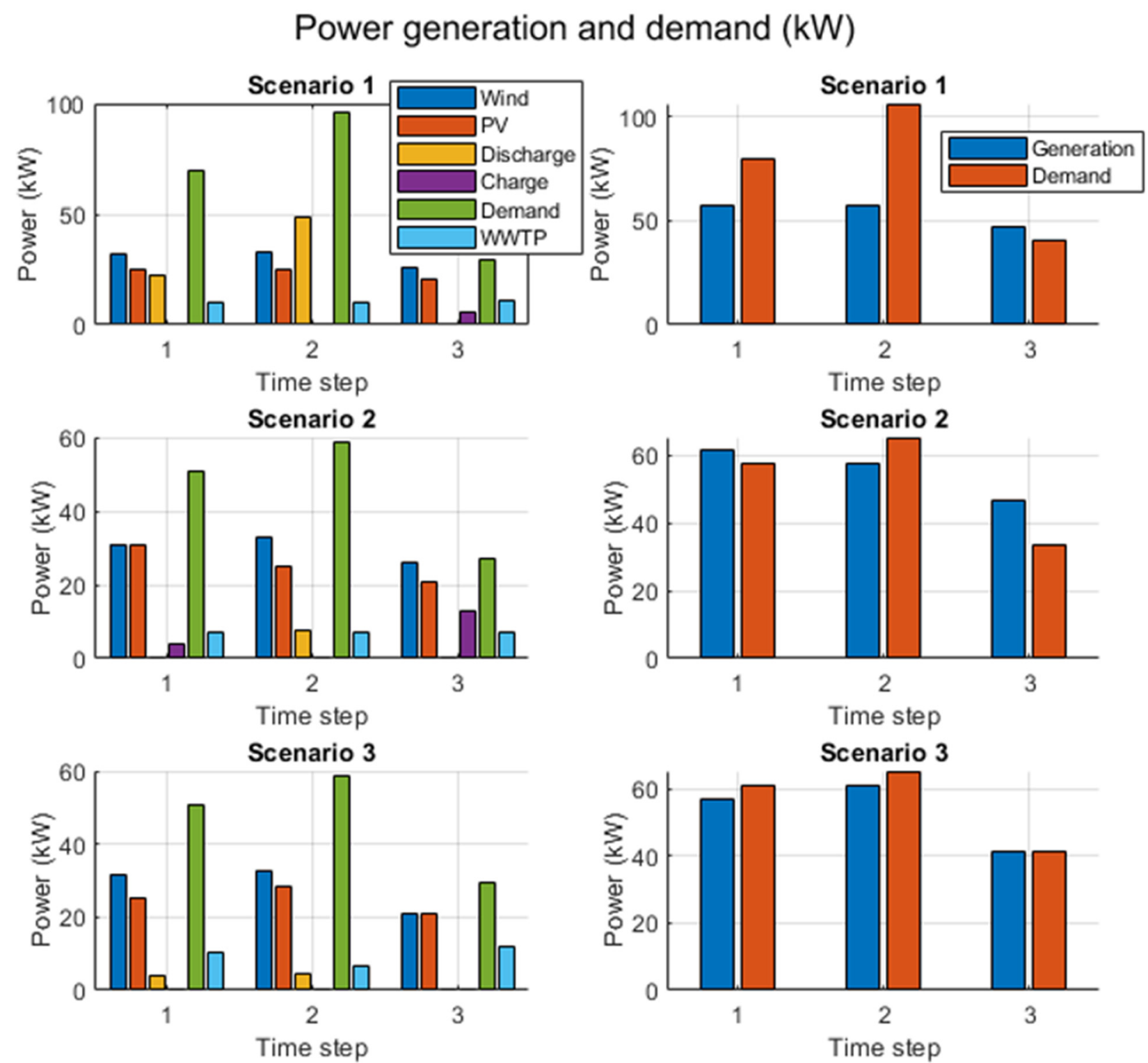

Figure 2. Graphs on the left show hourly power generation from individual sources at different time-steps and power demand at corresponding times, during the three representative scenarios. The graphs on the right side illustrate the total power generation (from wind and PV) and total power demand, for different scenarios and at different times.

The CES system stores power from the external source (grid) prior to time-step 1, as shown in Figure 3. The figure also shows the variations in the SOC of the battery as it undergoes charge and discharge cycles. As expected, the battery can be either charging or discharging at a given time-step, but not both.

Depending upon available generation and demand, there may be instances of demand response in order to ensure the power balance in the microgrid. Figure 4 shows the instances of load shedding in the microgrid. It can be seen that Customer 3 experiences load shedding during time-step 1 of scenario 1 (when generation is not enough to meet the demand). 
Hourly battery status and SOC (\%)
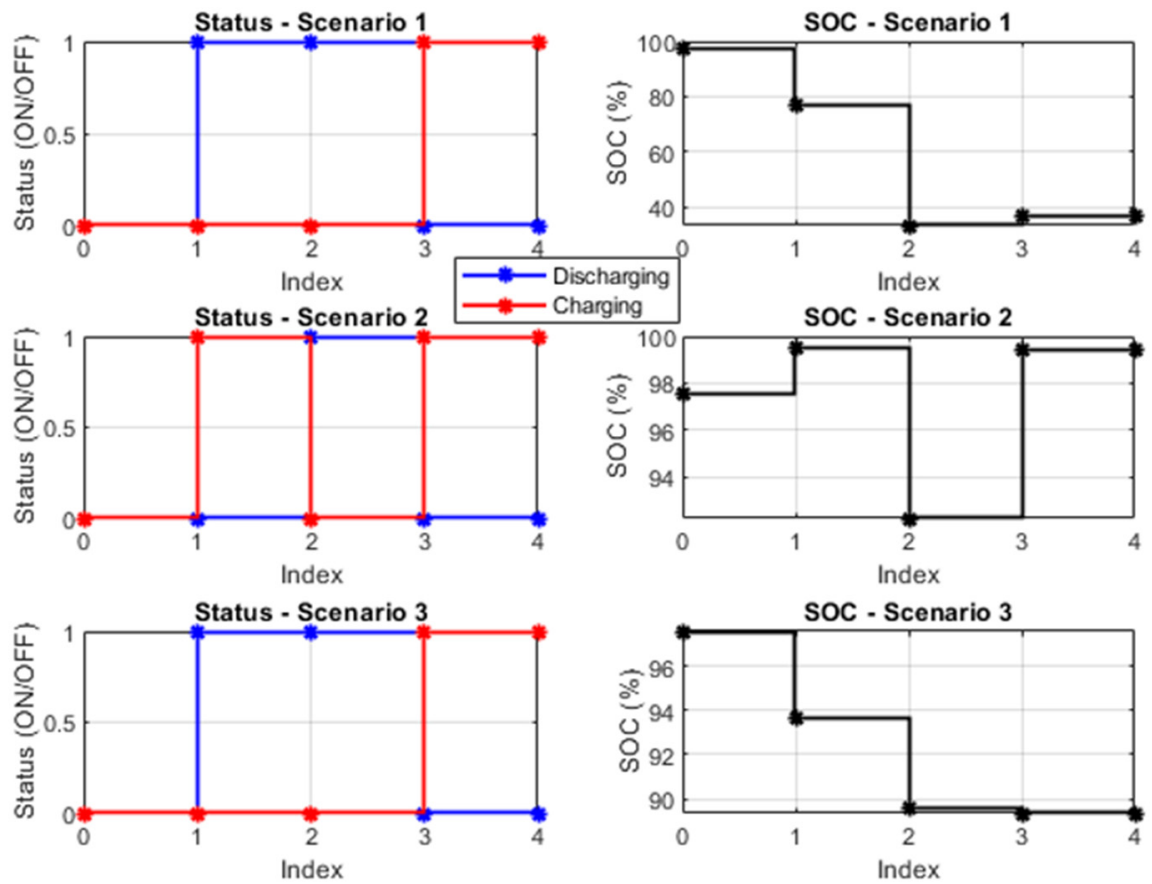

Figure 3. Hourly battery status (ON or OFF) and battery $S O C$ for the three scenarios. For all scenarios, the battery is initially charged at $98 \%$. As expected, scenario 1 indicates a significant drop in battery SOC, whereas in scenario 2, the battery undergoes some instances of charging. Scenario 3 also shows discharge; however, at a significantly lower rate than that of scenario 1.

\section{Customer Load Status}

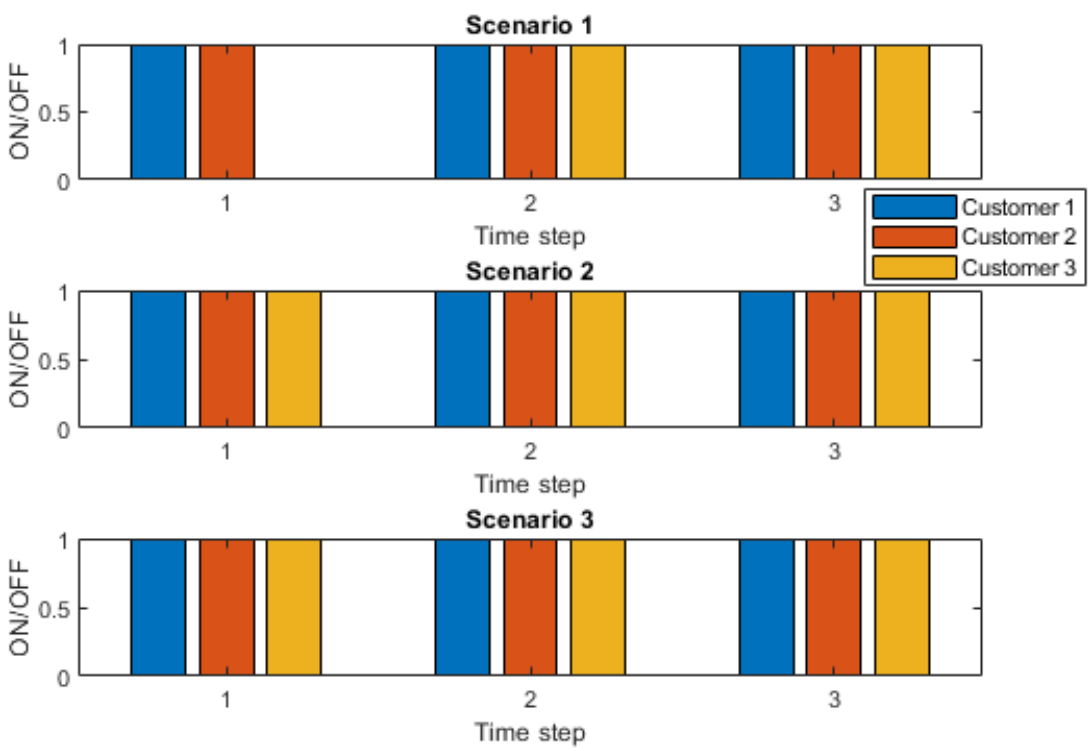

Figure 4. Load shedding or shifting instances during all three scenarios. During scenarios 2 and 3 , there is sufficient generation to meet the demand; therefore, no load shedding or shifting is performed. However, during scenario 1, customer 3 experiences a load shed for time-step 3 (although not during times 1 or 2 ).

Finally, Figure 5 shows the operation state of the water network. It can be seen that the WWTP starts supplying water to the ST at the beginning of time-step 3, which is then used to meet the water demand for that time-step. During the first two hours of operation 
there is no outflow from the WWTP, even though there is an increase in its volume. This is because it takes time for the WWTP to treat the wastewater received from the residents. As expected, the water volume in the ST decreases to respond to the water demand in the system. Depending upon the water demand rate for a given scenario, the water level in the ST may change at a higher or lower rate than other scenarios for the same time-step.

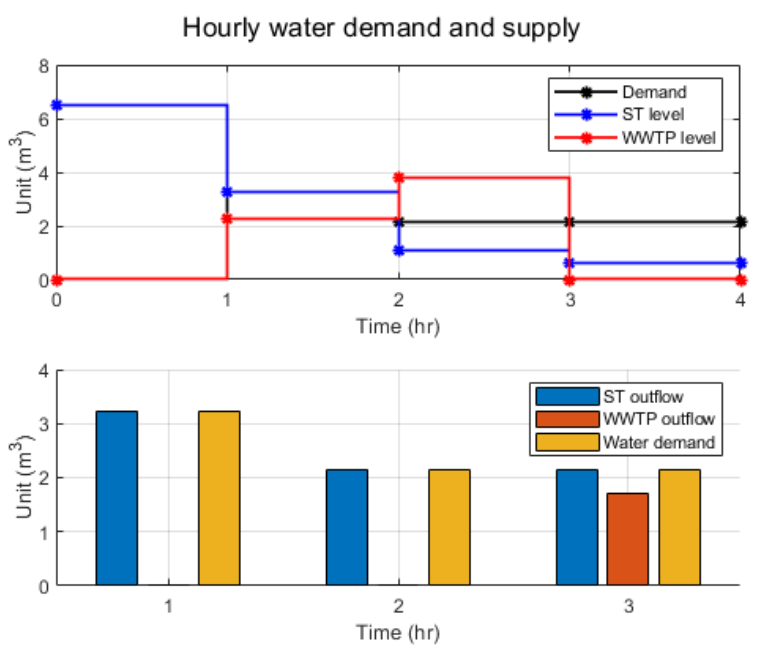

(a)

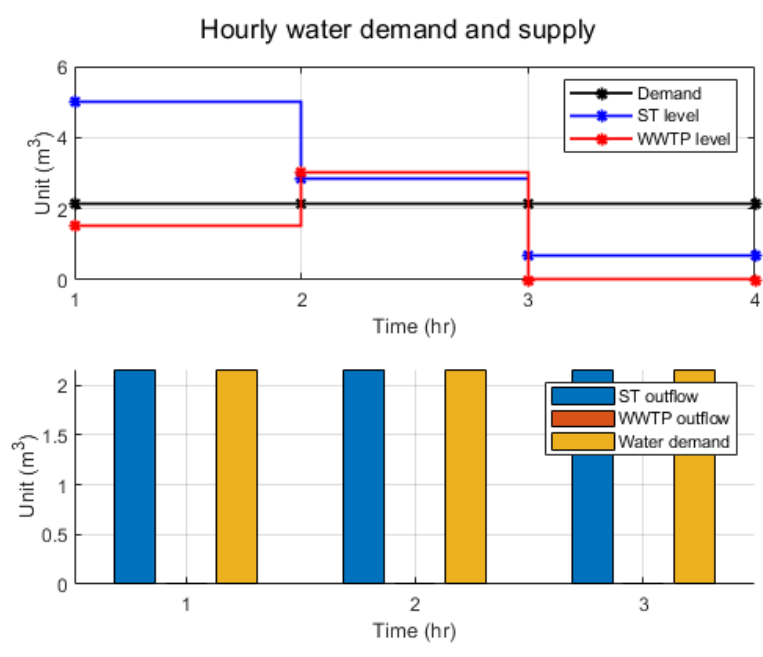

(b)

Figure 5. (a) Hourly water volume in the ST and WWTP during scenarios 1 and 3. During time-steps 1 and 2, the total water demand is being supplied by the outflow of the ST. There is no outflow from the WWTP for the first $2 \mathrm{~h}$ of operation, but there is an increase in its volume as the customers use water during these time-steps. During time-step 3, the WWTP starts supplying water to the ST, which in turn, supplies water to meet the demand, (b) Hourly water volume in the ST and WWTP during scenario 2. Since the ST tank has enough water to supply the low water demand for scenario 2 the WWTP does not need to be run for this scenario, as shown by zero outflow in (b). The wastewater that was stored in time-steps 1 and 2 will flow out of the WWTP as effluent, as indicated by the reduced water volume in the WWTP at time-step 3.

\section{Future Recommendations}

The proposed dispatch strategy provides a plan for resource allocation and demand response for smooth operation of a combined microgrid/micro-net. In the analysis presented in this paper, the focus was on frequency stability and ensuring power balance within the microgrid. This is not unusual, as often we assume that one of the energy resources (CES in this case) can act as a grid-forming unit and dictate the voltage. However, for a more detailed analysis, AC power flow equations as well as operational constraints for the reactive power can be included to ensure voltage stability and sufficient node voltage support. From a mathematical perspective, this can negatively affect the tractability of the optimization problem, as it introduces nonlinear terms. One way to avoid this, is to use Cartesian coordinates by breaking the node voltage equations into two: one for the real part and another for the imaginary part. Although this approach may still leave certain bilinear terms, the highly nonlinear sine and cosine terms will be avoided. An example of how this can be done for an unbalanced distribution network is shown in one of the author's previous work [54].

Incorporating reactive power into the equations necessitates adding an inequality constraint for generation resources to ensure that the lower and upper limits are not exceeded, and another one to maintain the limit on the apparent power $S$. For instance, for a generic source $g$ :

$$
\begin{gathered}
\forall g \in \mathrm{G}, \forall t \in \mathrm{T}, \forall s \in \mathrm{S}: Q_{g}^{\min } \leq Q_{g, t, s} \leq Q_{g}^{\max } \\
\forall g \in \mathrm{G}, \forall t \in \mathrm{T}, \forall s \in \mathrm{S}: S_{g, t, s}^{2}=P_{g, t, s}^{2}+Q_{g, t, s}^{2} \leq\left(S_{g}^{\max }\right)^{2}
\end{gathered}
$$


If desired, an inequality equation can also be added to ensure acceptable power flow limits through different series elements such as lines or transformers (if any).

$$
\forall l \in \mathrm{L}, \forall t \in \mathrm{T}, \forall s \in \mathrm{S}: S_{l, t, s} \leq S_{l}^{\max }
$$

It can be seen that these equations convert the optimization model into a nonlinear one, which requires special treatment for achieving acceptable tractability and convergence. Many researchers have proposed solution techniques based on quadratic programming, semidefinite programming, conic programming, or linearization and convexification of the model so that a solution can be obtained in polynomial time [55-58].

Lastly, it was assumed in this paper that the various scenarios and their probabilities (which were assumed to be equal) are known beforehand. This may not always be the case, however. In fact, finding the PDF of certain random variables may not be practical. This is especially true for variables that have highly stochastic variations. In those circumstances, the optimization model needs to be converted into a robust optimization model. Unlike the stochastic programming used in this paper, in robust optimization, no information is available about the random variables other than the range of values they may take. Then, the optimization problem is converted into a robust counterpart form, which ensures optimality even under worst-case conditions.

\section{Conclusions}

This paper presented a strategy for combined water and energy operation in an isolated community that is operating as a microgrid/micro-net. It is assumed that the community has been disconnected from the main power grid and the water distribution network due to a large disturbance such as a natural disaster and is expected to operate in a standalone mode. To do this, the community is assumed to be equipped with a battery system, renewable energy resources such as a wind turbine and multiple rooftop PV panels, a water storage tank, and a wastewater treatment plant that is capable of providing potable water. The problem was formulated as a two-stage stochastic optimization scenario, where the main objective is to supply the demand (water and power) as much as possible, at minimum cost, subject to the uncertainties in both demand and renewable generation. In the first stage, the problem determines the amount of water to be purchased from the outside world (if any) and the amount of power to be purchased from the main grid to initially charge the battery (if any). These are then optimally allocated using the secondstage recourse variables during the dispatch period. Recourse variables consist of the amount of charge/discharge of the battery at any point in time, the level of load shift/shed for each customer at any point in time, the operation status of the wastewater treatment facility, and the amount of water to be provided to the community by the storage tank. It was shown through a proof-of-concept case study that limited resources can be optimally allocated to allow for the continued operation of the community until services become available from the outside world. To improve tractability of the optimization problem, a sliding window approach was used where the problem was solved for a time horizon of 2-3 h at a time. Extending the simulation time can significantly increase the number of variables to be considered, which for off-the-shelf optimization software packages, may negatively impact the convergence rate or simulation time. However, such limitations will not exist in commercial optimization packages.

Author Contributions: Conceptualization, G.J. and S.M.; methodology, G.J. and S.M.; software, G.J.; validation, G.J.; formal analysis, G.J.; investigation, G.J.; resources, G.J. and S.M.; data curation, G.J.; writing —original draft preparation, G.J.; writing—review and editing, S.M.; visualization, G.J. and S.M.; supervision, S.M.; project administration, S.M. All authors have read and agreed to the published version of the manuscript.

Funding: This research received no external funding.

Conflicts of Interest: The authors declare no conflict of interest. 


\section{Nomenclature}

Indices and Sets

$i \quad$ Index used for customers (load points) in the microgrid

$k \quad$ Index used for time

$N \quad$ Set of load points in the community circuit

Scenarios (realizations of a random parameter) representing uncertain demand

$S \quad$ and generation as described in Table 1

$S \quad$ Set of scenarios

$t \quad$ Index used for time

Parameters and Input Data

A Area swept by the rotor of wind turbine $\left(\mathrm{m}^{2}\right)$

$c^{b} \quad$ purchasing and maintaining the battery divided by the maximum number of deep discharges available over its lifetime

$c^{u} \quad$ Cost of water purchase at the beginning of study period $\left(\$ / \mathrm{m}^{3}\right)$

$k^{w w} \quad$ Portion of water consumed that will be discharged as waste; the ratio of water inflow to households to water outflow to sewer system

$D_{i} \quad$ Contribution factor for customer $i$ : fraction of total electric demand in the system consumed by customer $i$.

Non-shiftable load factor for a customer $i$, i.e., the percentage of customer $i$

$d_{i} \quad$ demand which is non-shiftable.

M Cost of not meeting a power demand (penalty factor in \$)

$o_{i, t, s} \quad$ Occupancy at the residence of customer $i$ at time $t$ during scenario $s$

$p_{s} \quad$ Probability of occurrence of scenario $s$

$p^{w w}$

Power consumed at the wastewater treatment plant (WWTP) for treating $1 \mathrm{~m}^{3}$ of wastewater $\left(\mathrm{kW} / \mathrm{m}^{3}\right)$

$\mathrm{P}^{\mathrm{b}, \max } \quad$ Maximum available power provided by the battery $(\mathrm{kW})$

$P_{t, s}^{d} \quad$ Total active power consumption at time $t(\mathrm{~kW})$ during scenario $s$

$p^{\text {pump }}$

Power consumed to pump $1 \mathrm{~m}^{3}$ of treated wastewater from the WWTP to the community water storage tank $\left(\mathrm{ST} ; \mathrm{kW} / \mathrm{m}^{3}\right)$

$P_{i, t, s} \mathrm{PV}$

$P_{i}$ PV, STC

PV panel output at time $t(\mathrm{~kW})$ during scenario $s$ from costumer $i$

$P_{t, s} \mathrm{~W}$

PV panel power under standard test conditions (STCs; $\mathrm{kW}$ ) for customer $i$

$Q_{t, s} \mathrm{~d}$

Power provided by the wind turbine at time $t(\mathrm{~kW})$ during scenario

Total water demand in the system at time $\mathrm{t}\left(\mathrm{m}^{3}\right)$ during scenario $s$

This is the minimum amount of water considered to be necessary to ensure daily

$q^{\min }$ needs as per the World Health Organization estimation (50-100 L or $0.05-0.1 \mathrm{~m}^{3}$ per person per day)

$q^{\max }$

The designed maximum flow rate for the water network $\left(\mathrm{m}^{3} / \mathrm{s}\right)$

SOC max $^{\text {SOC }}$ Minimum allowable state-of-charge of the community battery (\%)

$\mathrm{SOC}_{0}$

$T$

Maximum allowable state-of-charge of the community battery (\%)

State-of-charge of the battery at the beginning of the study period (\%)

Time horizon of the study period ( $\mathrm{h}, \mathrm{min}$, etc.)

TSH

Maximum allowable number of times during a dispatch period that a customer

$V^{\mathrm{ST}, \mathrm{max}}$

may experience demand shifting. Naturally: $\mathrm{TSH}<\mathrm{T}$

$V^{\mathrm{ST}, \mathrm{min}}$

ST maximum capacity allowed $\left(\mathrm{m}^{3}\right)$

$V^{w w, \max } \quad$ Maximum capacity allowed in the WWTP $\left(\mathrm{m}^{3}\right)$

$V^{w w, \min } \quad$ WWTP minimum capacity that needs to be maintained $\left(\mathrm{m}^{3}\right)$

$w_{t, s} \quad$ Wind speed at the wind turbine location at time $t(\mathrm{~m} / \mathrm{s})$ during scenario $s$

$\alpha \quad$ Albert Betz constant

$\gamma \quad$ Self-discharge rate of the battery (p.u)

$\Delta \quad$ Duration of a single time-step (s)

$\eta^{c} / \eta^{d} \quad$ Charge/discharge efficiency of the battery (p.u)

$\rho_{a} \quad$ Air density $\left(\mathrm{kg} / \mathrm{m}^{3}\right)$

$\Phi_{i, t, s} \quad$ Incident solar irradiance at PV panel for consumer $i$ at time $t\left(\mathrm{~W} / \mathrm{m}^{2}\right)$ during

scenario $s$

$\Phi$ STC Incident solar irradiance at STC $\left(\mathrm{W} / \mathrm{m}^{2}\right)$ 


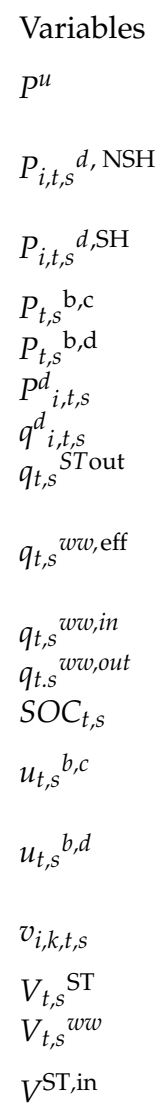

Power purchased from the utility to charge the battery at the beginning of the study period $(\mathrm{kW})$

Power consumed by non-shiftable loads of customer $i$ at time $t(\mathrm{~kW})$ during scenario $s$

Power consumption level of shiftable loads of customer $i$ at time $t(\mathrm{~kW})$ during scenario $s$

Power provided to charge the battery at time $t(\mathrm{~kW})$ during scenario $s$

Power discharged by the battery at time $t(\mathrm{~kW})$ during scenario $s$

Active power consumption at load point $i$ at time $t(\mathrm{~kW})$ during scenario $s$

Water consumption rate for customer $i$ at time $t\left(\mathrm{~m}^{3} / \mathrm{s}\right)$ during scenario $s$

Outgoing flow rate from the ST at time $t\left(\mathrm{~m}^{3} / \mathrm{s}\right)$ during scenario $s$

WWTP effluent flow rate at time $t\left(\mathrm{~m}^{3} / \mathrm{s}\right)$; the untreated wastewater is discharged from the WWTP to ensure that the total volume in the WWTP does not exceed its capacity during scenario $s$.

WWTP incoming flowrate at time $t\left(\mathrm{~m}^{3} / \mathrm{s}\right)$ during scenario $s$

WWTP outgoing flow (treated wastewater) at time $t\left(\mathrm{~m}^{3} / \mathrm{s}\right)$ during scenario $s$

State-of-charge of the battery at time $t(\%)$ during scenario $s$

Binary variable indicating battery charging status at time $t=1$ : charged, 0 : not charged) during scenario $s$

Binary variable indicating battery discharging status at time $t(=1$ : discharged, 0 : not discharged) during scenario $s$

Binary variable indicating if the shiftable appliance load has been shifted from time $k$ to a later time $t(=1$ : shifted, 0 : not shifted) during scenario $s$

Volume of water at the community ST at time $t\left(\mathrm{~m}^{3}\right)$ during scenario $s$

Volume of wastewater at the WWTP at time $t\left(\mathrm{~m}^{3}\right)$ during scenario $s$

Volume of water purchased and stored in the ST for the community so that it can be used during the daytime $\left(\mathrm{m}^{3}\right)$

\section{References}

1. Harvey, A.; Larson, A.; Patel, S. History of power: The evolution of the electric generation industry. Power Mag. 2017, 161, 32-47.

2. Delboni, L.F.N.; Marujo, D.; Balestrassi, P.P.; Oliveira, D.Q. Electrical power systems: Evolution from traditional configuration to distributed generation and microgrids. Microgrids Des. Implement. 2019, 1, 1-25.

3. Chen, S.; Song, S.; Li, L.; Shen, J. Survey on smart grid technology. Power Syst. Technol. 2009, 33, 1-7.

4. Doss-Gollin, J.; Farnham, D.J.; Lall, U.; Modi, V. How unprecedented was the February 2021 Texas cold snap? Environ. Res. Lett. 2021, 16, 064056. [CrossRef]

5. Wu, D.; Zheng, X.; Xu, Y.; Olsen, D.; Xia, B.; Singh, C.; Xie, L. An open-source model for simulation and corrective measure assessment of the 2021 Texas power outage. arXiv 2021, arXiv:2104.04146.

6. Anderson, J.; Bausch, C. Climate change and natural disasters: Scientific evidence of a possible relation between recent natural disasters and climate change. Policy Dep. Econ. Sci. Policy 2006, 2, 1-35.

7. Munich, R.E. Natural Catastrophe Year in Review 2013. In Proceedings of the Insurance Information Institute, Munich, Germany, 13 January 2013.

8. Banholzer, S.; Kossin, J.; Donner, S. The impact of climate change on natural disasters. Reducing Disaster Early Warn. Syst. Clim. Chang. 2014, 1, 21-49.

9. Noy, I.; Yonson, R. Economic vulnerability and resilience to natural hazards: A survey of concepts and measurements. Sustainability 2018, 10, 2850. [CrossRef]

10. Fothergill, A.; Peek, L.A. Poverty and disasters in the United States: A review of recent sociological findings. Nat. Hazards 2004, 32, 89-110. [CrossRef]

11. Desouza, K.C.; Flanery, T.H. Designing, planning, and managing resilient cities: A conceptual framework. Cities 2013, 35, 89-99. [CrossRef]

12. Jabareen, Y. Planning the resilient city: Concepts and strategies for coping with climate change and environmental risk. Cities 2013, 31, 220-229. [CrossRef]

13. Patel, S.S.; Rogers, M.B.; Amlôt, R.; Rubin, G.J. What do we mean by' community resilience'? A systematic literature review of how it is defined in the literature. PLoS Curr. 2017, 9. [CrossRef]

14. Romac, S. The Importance of Community Resilience: Developing the American Red Cross International Services Department in the New Hampshire Region. In Proceedings of the SIT Graduate Institute, Brattleboro, VT, USA, 7 May 2014.

15. Garcia, C.; Fearnley, C.J. Evaluating critical links in early warning systems for natural hazards. Environ. Hazards 2012, 11, 123-137. [CrossRef] 
16. Sauerborn, R.; Ebi, K. Climate change and natural disasters-Integrating science and practice to protect health. Glob. Health Action 2012, 5, 19295. [CrossRef]

17. Bastaminia, A.; Rezaei, M.R.; Saraei, M.H. Evaluating the components of social and economic resilience: After two large earthquake disasters Rudbar 1990 and Bam 2003. Jàmbá J. Disaster Risk Stud. 2017, 9, 1-12. [CrossRef]

18. Parra, D.; Swierczynski, M.; Stroe, D.I.; Norman, S.A.; Abdon, A.; Worlitschek, J.; O’Doherty, T.; Rodrigues, L.; Gillot, M.; Zhang, $\mathrm{X}$; et al. An interdisciplinary review of energy storage for communities: Challenges and perspectives. Renew. Sustain. Energy Rev. 2017, 79, 730-749. [CrossRef]

19. Parra, D.; Norman, S.A.; Walker, G.S.; Gillott, M. Optimum community energy storage system for demand load shifting. Appl. Energy 2016, 174, 130-143. [CrossRef]

20. Falco, G.J.; Webb, W.R. Water Microgrids: The future of water infrastructure resilience. Procedia Eng. 2015, 118, 50-57. [CrossRef]

21. Makropoulos, C.K.; Butler, D. Distributed water infrastructure for sustainable communities. Water Resour. Manag. 2010, 24, 2795-2816. [CrossRef]

22. Adeyeye, K.; Bairi, A.; Emmitt, S.; Hyde, K. Socially-integrated resilience in building-level water networks using smart microgrid+ net. Procedia Eng. 2018, 212, 39-46. [CrossRef]

23. Zhang, D.; Shah, N.; Papageorgiou, L.G. Efficient energy consumption and operation management in a smart building with microgrid. Energy Convers. Manag. 2013, 74, 209-222. [CrossRef]

24. Tuohy, A.; Meibom, P.; Denny, E.; O'Malley, M. Unit commitment for systems with significant wind penetration. IEEE Trans. power Syst. 2009, 24, 592-601. [CrossRef]

25. Palensky, P.; Dietrich, D. Demand side management: Demand response, intelligent energy systems, and smart loads. IEEE Trans. Ind. Inform. 2011, 7, 381-388. [CrossRef]

26. Liang, H.; Zhuang, W. Stochastic modeling and optimization in a microgrid: A survey. Energies 2014, 7, 2027-2050. [CrossRef]

27. Mehrjerdi, H. Modeling and optimization of an island water-energy nexus powered by a hybrid solar-wind renewable system. Energy 2020, 197, 117217. [CrossRef]

28. Parkinson, S.C.; Makowski, M.; Krey, V.; Sedraoui, K.; Almasoud, A.H.; Djilali, N. A multi-criteria model analysis framework for assessing integrated water-energy system transformation pathways. Appl. Energy 2018, 210, 477-486. [CrossRef]

29. Zhen, J.L.; Wu, C.B.; Liu, X.R.; Huang, G.H.; Liu, Z.P. Energy-water nexus planning of regional electric power system within an inexact optimization model in Tangshan City, China. J. Clean. Prod. 2020, 266, 121997. [CrossRef]

30. Wang, S.; Cao, T.; Chen, B. Water-energy nexus in China's electric power system. Energy Procedia 2017, 105, 3972-3977. [CrossRef]

31. Cherif, H.; Tnani, S.; Belhadj, J.; Silva, A.R. Optimal sizing and technical evaluation of energy and water system based on micro-hydric solar and wind sources. In Proceedings of the 2018 IEEE 16th International Conference on Industrial Informatics (INDIN), Porto, Portugal, 18-20 July 2018; pp. 1018-1023.

32. Fooladivanda, D.; Domínguez-García, A.D.; Sauer, P.W. Utilization of water supply networks for harvesting renewable energy. IEEE Trans. Control. Netw. Syst. 2018, 6, 763-774. [CrossRef]

33. Li, Q.; Yu, S.; Al-Sumaiti, A.; Turitsyn, K. Modeling and co-optimization of a micro water-energy nexus for smart communities. In Proceedings of the 2018 IEEE PES Innovative Smart Grid Technologies Conference Europe (ISGT-Europe), Porto, Portugal, 18-20 July 2018; pp. 1-5.

34. Santhosh, A.; Farid, A.M.; Youcef-Toumi, K. Real-time economic dispatch for the supply side of the energy-water nexus. Appl. Energy 2014, 122, 42-52. [CrossRef]

35. Eckroad, S.; Gyuk, I. EPRI-DOE handbook of energy storage for transmission \& distribution applications. Electr. Power Res. Inst. Inc. 2003. Available online: https://www.sandia.gov/ess-ssl/publications/ESHB $\% 201001834 \% 20$ reduced $\% 20$ size.pdf (accessed on 20 September 2021).

36. Madaeni, S.H.; Sioshansi, R. The impacts of stochastic programming and demand response on wind integration. Energy Syst. 2013, 4, 109-124. [CrossRef]

37. Papavasiliou, A.; Oren, S.S. Coupling wind generators with deferrable loads. In Proceedings of the 2008 IEEE Energy 2030 Conference, Atlanta, GA, USA, 17-18 November 2008; pp. 1-7.

38. Jowitt, P.W.; Germanopoulos, G. Optimal pump scheduling in water-supply networks. J. Water Resour. Plan. Manag. 1992, 118, 406-422. [CrossRef]

39. Menke, R.; Abraham, E.; Parpas, P.; Stoianov, I. Demonstrating demand response from water distribution system through pump scheduling. Appl. Energy 2016, 170, 377-387. [CrossRef]

40. Ioannou, A.; Fuzuli, G.; Brennan, F.; Yudha, S.W.; Angus, A. Multi-stage stochastic optimization framework for power generation system planning integrating hybrid uncertainty modelling. Energy Econ. 2019, 80, 760-776. [CrossRef]

41. Huang, K.; Ahmed, S. The value of multistage stochastic programming in capacity planning under uncertainty. Oper. Res. 2009, 57, 893-904. [CrossRef]

42. Peng, X.; Jirutitijaroen, P. A probabilistic unit commitment problem with photovoltaic generation system. In Proceedings of the TENCON 2009-2009 IEEE Region 10 Conference, Singapore, 23-26 January 2009; pp. 1-6.

43. Lubin, M.; Petra, C.G.; Anitescu, M.; Zavala, V. Scalable stochastic optimization of complex energy systems. In Proceedings of the 2011 International Conference for High Performance Computing, Networking, Storage and Analysis, Seattle, WA, USA, 12-18 November 2011; pp. 1-10. 
44. Kuznia, L.; Zeng, B.; Centeno, G.; Miao, Z. Stochastic optimization for power system configuration with renewable energy in remote areas. Ann. Oper. Res. 2013, 210, 411-432. [CrossRef]

45. Zheng, J.; Kou, Y.; Li, M.; Wu, Q. Stochastic optimization of cost-risk for integrated energy system considering wind and solar power correlated. J. Mod. Power Syst. Clean Energy 2019, 7, 1472-1483. [CrossRef]

46. Growe-Kuska, N.; Heitsch, H.; Romisch, W. Scenario reduction and scenario tree construction for power management problems. In Proceedings of the 2003 IEEE Bologna Power Tech Conference, Bologna, Italy, 23-26 June 2003; Volume 3, p. 7.

47. Römisch, W. Scenario reduction techniques in stochastic programming. In Proceedings of the International Symposium on Stochastic Algorithms, Sapporo, Japan, 26-28 October 2009; pp. 1-14.

48. Joshi, G.; Mohagheghi, S. Energy and Water Co-Optimization for the Resilient Neighborhood of Future. In Proceedings of the 2020 IEEE Industry Applications Society Annual Meeting, Detroit, MI, USA, 10-16 October 2020; pp. 1-8.

49. USGS. Water Science School. 2020. Available online: https://www.usgs.gov/special-topic/water-science-school/science (accessed on 15 July 2021).

50. US Energy Information Administration. Electricity Explained Use of Electricity. 2020. Available online: https://www.eia.gov/ energyexplained/electricity/use-of-electricity.php (accessed on 15 July 2021).

51. Choobineh, M.; Speake, A.; Harris, M.; Tabares-Velasco, P.C.; Mohagheghi, S. End-user-aware community energy management in a distribution system exposed to extreme temperatures. IEEE Trans. Smart Grid 2018, 10, 3753-3764. [CrossRef]

52. Goodrich, A.; James, T.; Woodhouse, M. Residential, Commercial, and Utility-Scale Photovoltaic (PV) System Prices in the United States: Current Drivers and Cost-Reduction Opportunities; National Renewable Energy Lab. (NREL): Golden, CO, USA, 2012.

53. (CEC) Commission California Energy. California Code of Regulations Title 20. 2016. Available online: https:/ /www.epa.gov/ sites/production/ files/2017-10/documents / ws-commercialbuildings-waterscore-residential-kitchen-laundry-guide.pdf (accessed on 27 February 2020).

54. Alboaouh, K.; Mohagheghi, S. Voltage, var and watt optimization for a distribution system with high PV penetration: A probabilistic study. Electr. Power Syst. Res. 2020, 180, 106159. [CrossRef]

55. Yeh, H.-G.; Gayme, D.F.; Low, S.H. Adaptive VAR control for distribution circuits with photovoltaic generators. IEEE Trans. Power Syst. 2012, 27, 1656-1663. [CrossRef]

56. Jabr, R.A. A conic quadratic format for the load flow equations of meshed networks. IEEE Trans. Power Syst. 2007, 22, 2285-2286. [CrossRef]

57. Bai, X.; Wei, H.; Fujisawa, K.; Wang, Y. Semidefinite programming for optimal power flow problems. Int. J. Electr. Power Energy Syst. 2008, 30, 383-392. [CrossRef]

58. Contaxis, G.C.; Delkis, C.; Korres, G. Decoupled optimal load flow using linear or quadratic programming. IEEE Trans. Power Syst. 1986, 1, 1-7. [CrossRef] 